\title{
Quantification of metal in the hair of copper miners in Katanga Province, Democratic Republic of Congo
}

\author{
Myriam Molayi Elenge*, Jean-Claude Aubry, Luc Jacob and Christophe De Brouwer
}

Free University of Brussels, School of Public Health, Environmental Health and Occupational Health PO Box 593, Route de Lennik 808,1070 Brussels - Belgium

\begin{abstract}
This study aims to demonstrate the exposure of artisanal miners to the contents of mineralised gangue and to assess whether the different workstations and their related operating processes potentiate such exposure. The population sampled $(n=100)$ consisted of artisanal miners operating in the mine of Ruashi, in the south of the Katanga copper belt. We made use of hair as a biomarker and performed our analyses using ICP-MS. According to recommendations from the Agency for Toxic Substances and Disease Registry, we have compared our results to those of an unexposed population living in the same area in order to point out the occupational origins of such exposure. In our hair analysis, we identified and quantified 22 elements. For almost all of these elements, the artisanal miners had much higher values as compared to the control population. In addition, non-diggers had higher levels than diggers for almost all of the elements that could be directly linked to those present in the mineralised gangue. Median values obtained for the artisanal miners were systematically higher than those of the control population, reflecting a higher than normal exposure. Such differences between the two sample populations can only be explained by the occupational (mining) origin of exposure, since the living environment, hair nature, sampling method, and analysis techniques were the same for both populations. Medians within the miner samples showed different exposure profiles for non-diggers versus diggers, resulting from the fact that non-diggers were more exposed to the mineralised gangue. The results attest to the reality and the large extent to which artisanal miners in Katanga Province are exposed to chemical components of mineralised gangue. This exposure is more significant within the workstations related to the raw mineral processing phase as opposed to the extraction phase.
\end{abstract}

\section{Introduction}

Artisanal mining has several risks, including toxicological hazards resulting from prolonged exposure to chemical components of the exploited mineralised gangue [1]. Indeed, results of ore sample analysis from the mineralogical database of Central Africa Royal Museums [2] show that the specimens are a combination of several substances.

For example, samples from the district of Ruashi show different compositions. Some are composed of malachite $\left(\mathrm{Cu}_{2} \mathrm{Co}_{3}(\mathrm{OH})_{2}\right)$, either alone or in association with heterogenite $\left(\mathrm{Co}^{3+} \mathrm{O}(\mathrm{OH})\right)$ and hematite $\left(\mathrm{Fe}_{2} \mathrm{O}_{3}\right)$, while other have a predominance of magnetite $\left(\mathrm{Fe}^{3+}{ }_{2} \mathrm{Fe}^{2+} \mathrm{O}_{4}\right)$ with some malachite, and still others have a predominance of heterogenite with lesser amounts of malachite and chrysocolla $\left((\mathrm{Cu}, \mathrm{Al})_{2} \mathrm{H}_{2} \mathrm{Si}_{2} \mathrm{O}_{5}(\mathrm{OH})_{4} \mathrm{r}\left(\mathrm{H}_{2} \mathrm{O}\right)\right)$. Other samples collected from the same site contain cornetite $\left(\mathrm{Cu}_{3}\left(\mathrm{PO}_{4}\right)(\mathrm{OH})_{3}\right.$, chalcotite $\left(\mathrm{Cu}_{2} \mathrm{~S}\right)$, katangite $\left(\mathrm{Cu}_{8}\left(\mathrm{Si}_{4} \mathrm{O}_{11}\right)_{2}(\mathrm{OH})_{4} \cdot \mathrm{H}_{2} \mathrm{O}\right)$, sphalerite $(\mathrm{ZnS})$ or metatorbernite $\left(\mathrm{Cu}\left(\mathrm{UO}_{2}\right)_{2}\left(\mathrm{PO}_{4}\right)_{2} \cdot 8 \mathrm{H}_{2} \mathrm{O}\right)$, associated with heterogenite.

In addition to minerals that outcrop at depths of 15-20 m, which are generally oxides, hydroxides, carbonate or silicates (depending on the circumstances), artisanal miners are also exposed to sulphurous mineral types, such as sulphates and vanadates [3], which are present in backfills from industrial clearing of low mineral layers [4].

Different descriptive studies of operating processes in artisanal mines have indicated that prevention regarding toxicological hazards related to the exposure to these harmful substances is not taken into consideration [5]. For this reason, analysis of biomarker samples taken from artisanal miners should reflect significant contamination of this population, due to the occupational exposure. Our objectives in this study include demonstrating the exposure of artisanal miners to mineralised gangue contents, as well as assessing the various workstations within this activity in order to determine whether the operating processes specific to each of these workstations potentiate such exposure.

\section{Materials and Methods}

\section{Sampling and data collection}

The target population in this study consists of all artisanal miners in the Province of Katanga. The sample population is made up of artisanal miners operating in the mine of Ruashi, formerly known as Star Mine, located in the south of the Katanga copper belt. The sample consists of 100 miners.

Our sampled population (systematic random sampling) consisted of artisanal miners whose total headcount amounted to 1014 individuals. In order to take part in the survey, each candidate had to fulfill 5 conditions, namely he had to: be a artisanal miner, have worked for over 12 calendar months at the Ruashi mine, be registered on the local census, not to have worked in any industrial mine and having agree to take part in the survey.

\section{Samples preparation and analysis}

We used hair analysis to highlight the exposure of artisanal miners to harmful substances. Use of this biomarker was justified by its ability

*Corresponding author: Myriam Molayi Elenge, Free University of Brussels, School of Public Health, Environmental Health and Occupational Health PO Box 593, Route de Lennik 808, 1070 Brussels - Belgium, Tel: +32(0)2 555 4027; Fax: +32 (0)2 555 4049; E-mail: melengem@ulb.ac.be

Received September 29, 2011; Accepted November 29, 2011; Published December 01, 2011

Citation: Elenge MM, Aubry J, Jacob L, Brouwer CD (2011) Quantification of metal in the hair of copper miners in Katanga Province, Democratic Republic of Congo. J Environment Analytic Toxicol 1:114. doi:10.4172/2161-0525.1000114

Copyright: (c) 2011 Elenge MM, et al. This is an open-access article distributed under the terms of the Creative Commons Attribution License, which permits unrestricted use, distribution, and reproduction in any medium, provided the original author and source are credited. 
to detect small and even trace amounts of elements [6]. Compared to other biomarkers, hair has the added benefits of indicating the existence of chronic exposure and enabling retrospective analysis of identical samples. Hair samples were collected at the neck, in accordance with recommendations from the Society of Hair Testing [7]

Prior to analysis, hair samples were cleansed in order to decontaminate them from dust and other environmental pollutants. Then, the samples were mineralised in order to obtain a completely liquid solution [8]. Only reagents that leave no traces were used, such as ultra-pure water from Merck (Merck ultra-pure $\mathrm{H}_{2} \mathrm{O}$ ) and deionised water, which were treated in the DI 611 Ariu Sartorius to obtain a solution of $18.2 \mathrm{M} \Omega$.

Washing was performed in three stages; firstly, $20 \mathrm{mg}$ of hair was mixed in $5 \mathrm{ml}$ of acetone for $30 \mathrm{~s}$, then was mixed in ultrapure water at $40{ }^{\circ} \mathrm{C}$ for another $30 \mathrm{~s}$, and finally dried in an incubator at $40{ }^{\circ} \mathrm{C}$. ineralization and digestion were also carried out in three stages of acid treatment in an Anton Paar brand microwave oven (model 2000 MW), with a six-sealed Teflon reactor carousel, using a mixture of $20 \mathrm{mg}$ hair in $1 \mathrm{ml}$ of $\mathrm{HNO}_{3}, 0.2 \mathrm{ml}$ of $\mathrm{H}_{2} \mathrm{O}_{2}, 0.2 \mathrm{ml}$ of $\mathrm{HCl}, 4.6 \mathrm{ml}$ of water, and $250 \mathrm{mg}$ of gold per litre of ultrapure water. This mixture was first placed in the oven for 5 minutes, at $100 \mathrm{~W}$ and $500 \mathrm{~W}$. Next, the mixture cooked for 15 minutes at $800 \mathrm{~W}$, and then at $0 \mathrm{~W}$ with the fan set to level three for 30 minutes. At the end, the hair was well mineralised and was reduced to a total volume of $10 \mathrm{ml}$ using ultrapure water.

The mineralised hair samples were then analysed to establish levels of metals and metalloids. Our results were then compared with those of the reference material "The certified reference material NCZC 81002 human hair" from the China National Centre for Analytical Procedures Control. Detection and quantification of metals and metalloids by ICP-MS was carried out on a type ELEMENT 2 device from ThermoOptek. The calibration of this device is clearly presented in Table 1 . We used coefficient of variation $\left(\mathrm{CV}=100^{\star}\right.$ Standard deviation/average) to ensure that the results obtained using ICP-MS allow for repeatability of our hair analysis.

\section{Statistical methods}

The determination of the occupational nature of a study normally requires the use of reference values. Since these values were not

\begin{tabular}{|c|c|c|}
\hline STEP & SETTINGS & VALUES \\
\hline \multirow{4}{*}{ Plasma } & RF Power & $1.1 \mathrm{Kw}$ \\
\hline & Argon cooling gas & $15.451 / \mathrm{min}$ \\
\hline & Argon subsidiary gas & $1.381 / \mathrm{min}$ \\
\hline & Argon nebulizer gas & $1.031 / \mathrm{min}$ \\
\hline Selection of samples & Peristaltic pump & 12 rpm \\
\hline \multirow{2}{*}{ nebulizer } & Conic nebulizer & Glass expansion, type Micro Mist \\
\hline & Spray chamber & Cyclonic, glass expansion \\
\hline \multirow{2}{*}{ Ion sampling } & Sample cone & Nickel $1.00 \mathrm{~mm}$ dia \\
\hline & Skimmer cone & Nickel $0.75 \mathrm{~mm}$ dia \\
\hline Torch & & Quartz, injector prototype 3 \\
\hline \multirow{2}{*}{ Empty } & Primary empty & $1.25 \mathrm{E}-3 \mathrm{mbar}$ \\
\hline & Secondary empty & $2.45 \mathrm{E}-7 \mathrm{mbar}$ \\
\hline \multirow{6}{*}{ Measurement } & \multirow{2}{*}{ Sample taking } & $3 \mathrm{~min} 32 \mathrm{sec}$ \\
\hline & & 3runs (20 elements in LR and MR) \\
\hline & Rinsing out & $60 \mathrm{sec}$ \\
\hline & Resolution & Low (LR) or Average (MR) \\
\hline & Calibration & External \\
\hline & Internal standard & Rhodium \\
\hline
\end{tabular}

Table 1: Condition and parameters of ICP-MS. available, we have compared our results to hair analysis of an unexposed population living in the same area - students of the University of Lubumbashi [9]-in accordance with the recommendations of the panel discussion of the Agency for Toxic Substances and Disease Registry (ATSDR) [10]. Statistical analyses were based on the use of median with the dispersion measures of either interquartile range or the $5^{\text {th }}$ and $95^{\text {th }}$ percentiles, as appropriate. The Man Whitney nonparametric test, performed with SPSS 17, allowed for the proper comparison of median levels of metals.

\section{Results}

\section{Socio-demographic description of the sample population}

The median age of miners (25 years) and their interquartile range (7 years) match those of control population, the students. While $61 \%$ of the miners were tobacco (cigarette) users, this percentage was only $50,5 \%$ for the students.

Our sample of miners, when split according to their workstations, is comprised of $61 \%$ diggers and $39 \%$ non-diggers. The median age of diggers was found to be 26 years with an interquartile range of 7 years, whereas the median age for non-diggers was 24 years with an interquartile range of 4 years. Although not statistically significant, this difference in interquartile ranges explains why $69 \%$ of non-diggers were 25 years or less, while being only $44 \%$ among diggers. While $74 \%$ of diggers were smokers, this percentage dropped to $41 \%$ among nondiggers.

In our sample, the median consumption of smokers was 10 cigarettes per day, with an interquartile range of 5 cigarettes. It should also be noted that the difference between the percentage of tobacco users in diggers (74\%) versus non-diggers (41\%) was statistically significant. On the other hand, $11 \%$ of non-diggers had three or more years of experience, whereas $34 \%$ of diggers had this experience; this difference was also found to be statistically significant.

\section{Description of metal traces content in hair}

Table 2 shows the values for the 22 metals that we have identified and quantified in the miner hair samples. In comparison with the mineral content of the hair of University of Lubumbashi students, Table 3 shows that the values present in the hair of artisanal miners are much higher for most of the identified and quantified elements. Results from the Man Whitney nonparametric test of medians also show that the difference between the two groups is statistically significant.

A more in-depth analysis of the hair samples shows that contamination is dependent on the workstation: diggers show less contamination than non-diggers. Table 4 shows than non-diggers have higher levels than diggers for elements that can be directly linked to metals present in different compositions of the mineralised gangue. For almost all of these elements, non-diggers have higher values than diggers, except for thallium and vanadium. In addition, even though the medians observed within these two subgroups are quite similar, the $5^{\text {th }}$ and $95^{\text {th }}$ percentiles clearly show that diggers and non-diggers do not have the same profile.

\section{Discussion}

\section{Comparison of miner contamination versus student contamination}

It is important to note that any sample of hair shows the same variety of elements, regardless of whether or not the person has been 
Citation: Elenge MM, Aubry J, Jacob L, Brouwer CD (2011) Quantification of metal in the hair of copper miners in Katanga Province, Democratic Republic of Congo. J Environment Analytic Toxicol 1:114. doi:10.4172/2161-0525.1000114

Page 3 of 6

\begin{tabular}{|c|c|c|c|c|c|}
\hline Metals & Median $\mu \mathrm{g} / \mathrm{g}$ & $5^{\text {th }}$ percentile $\mu \mathrm{g} / \mathrm{g}$ & $95^{\text {th }}$ percentile $\mu \mathrm{g} / \mathrm{g}$ & Average $\mu \mathrm{g} / \mathrm{g}$ & Standard deviation $\mu \mathrm{g} / \mathrm{g}$ \\
\hline Aluminum & $3,236.425$ & 685.830 & $8,249.292$ & $3,345.500$ & $2,219.537$ \\
\hline Antimony & 0.550 & 0.173 & 1.423 & 0.606 & 0.375 \\
\hline Silver & 15.985 & 2.980 & 153.707 & 38.833 & 55.924 \\
\hline Barium & 27.054 & 13.442 & 83.421 & 33.032 & 20.299 \\
\hline Beryllium & 0.109 & 0.023 & 0.753 & 0.196 & 0.241 \\
\hline Cadmium & 2.152 & 0.153 & 5.795 & 2.336 & 1.942 \\
\hline Calcium & $3,083.189$ & $1,272.223$ & $7,700.213$ & $3,605.090$ & $2,042.934$ \\
\hline Cerium & 3.406 & 0.623 & 7.529 & 3.408 & 2.269 \\
\hline Chrome & 14.221 & 3.765 & 70.311 & 19.557 & 19.551 \\
\hline Cobalt & 165.428 & 82.568 & $6,322.123$ & 896.419 & $1,894.201$ \\
\hline Copper & $1,024.496$ & 426.567 & $12,511.666$ & $2,267.023$ & $3,459.290$ \\
\hline Tin & 1.722 & 0.748 & 4.369 & 1.976 & 1.080 \\
\hline Iron & $5,977.558$ & $2,692.502$ & $73,091.729$ & $13,448.235$ & $20,774.764$ \\
\hline Magnesium & 420.499 & 225.000 & $1,296.397$ & 516.781 & 302.719 \\
\hline Manganese & 371.496 & 155.996 & $5,283.831$ & 943.976 & $1,399.398$ \\
\hline Mercury & 4.397 & 1.148 & 12.820 & 5.082 & 3.233 \\
\hline Molybdenum & 0.580 & 0.159 & 1.556 & 0.605 & 0.358 \\
\hline Nickel & 20.743 & 9.076 & 87.038 & 32.039 & 36.190 \\
\hline Lead & 67.817 & 14.606 & 247.882 & 83.105 & 68.651 \\
\hline Thallium & 0.081 & 0.029 & 0.272 & 0.101 & 0.070 \\
\hline Vanadium & 66.414 & 33.740 & $1,700.389$ & 251.621 & 481.847 \\
\hline Zinc & 328.491 & 193.945 & 942.206 & 384.415 & 245.468 \\
\hline
\end{tabular}

Table 2: Metals contents in the hair of hand miners.

\begin{tabular}{|c|c|c|c|c|c|c|}
\hline \multirow{2}{*}{ Metals } & \multicolumn{3}{|c|}{ Artisanal miners $(\mathrm{N}=100)$} & \multicolumn{3}{|c|}{ UNILU's Students ( $\mathrm{N}=109)$} \\
\hline & Median & $5^{\text {th }}$ percentile & $95^{\text {th }}$ percentile & Median & $5^{\text {th }}$ percentile & $95^{\text {th }}$ percentile \\
\hline Aluminum & $3,236.425$ & 685.830 & $8,249.292$ & 380.379 & 244.454 & 707.794 \\
\hline Antimony & 0.550 & 0.173 & 1.423 & 0.076 & 0.029 & 0.139 \\
\hline Silver & 15.985 & 2.980 & 153.707 & 0.151 & 0.050 & 0.379 \\
\hline Barium & 27.054 & 13.442 & 83.421 & 2.763 & 1.918 & 4.278 \\
\hline Beryllium & 0.109 & 0.023 & 0.753 & 0.020 & 0.001 & 0.006 \\
\hline Cadmium & 2.152 & 0.153 & 5.795 & 0.322 & 0.118 & 0.487 \\
\hline Calcium & $3,083.189$ & $1,272.223$ & $7,700.213$ & 517.859 & 252.870 & 830.368 \\
\hline Cerium & 3.406 & 0.623 & 7.529 & 0.421 & 0.305 & 0.535 \\
\hline Chrome & 14.221 & 3.765 & 70.311 & 1.161 & 0.680 & 2.124 \\
\hline Cobalt & 165.428 & 82.568 & $6,322.123$ & 1.667 & 0.802 & 2.402 \\
\hline Copper & $1,024.496$ & 426.567 & $12,511.666$ & 49.859 & 15.965 & 232.124 \\
\hline Tin & 1.722 & 0.748 & 4.369 & 0.213 & 0.100 & 0.613 \\
\hline Iron & $5,977.558$ & $2,692.502$ & $73,091.729$ & 235.247 & 138.867 & 307.412 \\
\hline Magnesium & 420.499 & 225.000 & $1,296.397$ & 64.893 & 41.949 & 107.700 \\
\hline Manganese & 371.496 & 155.996 & $5,283.831$ & 8.901 & 4.352 & 13.350 \\
\hline Mercury & 4.397 & 1.148 & 12.820 & 0.341 & 0.190 & 0.598 \\
\hline Molybdenum & 0.580 & 0.159 & 1.556 & 0.115 & 0.078 & 0.209 \\
\hline Nickel & 20.743 & 9.076 & 87.038 & 0.487 & 0.252 & 0.964 \\
\hline Lead & 67.817 & 14.606 & 247.882 & 17.774 & 6.812 & 26.178 \\
\hline Thallium & 0.081 & 0.029 & 0.272 & 0.008 & 0.007 & 0.013 \\
\hline Vanadium & 66.414 & 33.740 & $1,700.389$ & 0.791 & 0.440 & 1.400 \\
\hline Zinc & 328.491 & 193.945 & 942.206 & 52.185 & 35.586 & 66.739 \\
\hline
\end{tabular}

Table 3: Metals track contents in hand miners and in the students of Lubumbashi University.

exposed to contaminants [11]. Thus, it could be said that the presence of these elements in the hair of artisanal miners is not necessarily linked to occupation. However, the fact that the medians for the artisanal miners are systematically higher than the 95th percentile of the unexposed student population shows that the miners have higher than normal exposure. Furthermore, the fact that the differences between the miners and students were statistically significant for almost all metals identified additionally points to the occupational origin of the miners' exposure.
Because both the student and miner sample populations came from the same Province, these statistically significant differences cannot be explained by variation in living environments [12], hair nature, sampling method, or analysis techniques of hair samples. In addition, even the diet is similar for both populations, and thus can be discarded as a cause of variability in these contamination values [13].

Our results confirm those from previous studies that point to the significant exposure of artisanal miners to toxins used in this type of mining. After analysing samples of hair, urine, and blood of artisanal 
gold miners in Tanzania, and comparing them to similar samples of the general population in the same area, Bose-O'Reilly et al. [14] demonstrated that hair of artisanal miners contained higher mercury levels than the general population. The same analysis was carried out for gold miners in Indonesia, and the same conclusions were reached [15].

It can be deduced from our study that the exposure of artisanal miners of the Katanga Province should be treated with concern, especially when it is considered that for some metals, reference values for the control (student) population were higher than those for unexposed populations in other regions [16]. This sheds light on the importance of environmental exposure, which has been previously highlighted by Banza and Nemery [17] in urine analysis; for many metal and trace elements, they obtained significantly higher values for the general population of Katanga than for other non-industrial populations. Even if there is no correlation between metal levels in hair and urine, these results confirm the extent of environmental exposure of individuals living in the copper belt in Katanga. Indeed, evidence of environmental exposure was even found in the analysis of fish living in rivers affected by artisanal mining, through the detection of metals such as cadmium, and lead [18].

If occupational origin is not considered, it is difficult to fully explain the differences observed between the artisanal miner and control populations because almost all of the identified metals, even those that are not examined in previous literature, are a part of the chemical composition of the exploited ore. It should nevertheless be pointed out that a microprobe chemical analysis of heterogenite ore [19] showed the following elements: copper $(\mathrm{Cu})$, silicon $(\mathrm{Si})$, aluminium $(\mathrm{Al})$, manganese $(\mathrm{Mn})$, and iron $(\mathrm{Fe})$, with a smaller extent of phosphorous $(\mathrm{P})$, chlorine $(\mathrm{Cl})$, calcium $(\mathrm{Ca})$, barium $(\mathrm{Ba})$, vanadium $(\mathrm{V})$, tin $(\mathrm{Sn})$, uranium $(\mathrm{U})$, and lead $(\mathrm{Pb})$. Further analyses by ICP-MS have increasingly highlighted traces of nickel (Ni), zinc (Zn), arsenic (As), and molybdenum (Mo). Differences between the artisanal miner and control populations, for elements that were not previously identified in the exploited gangues, are a challenge to explain. It is clear that more detailed chemical analyses of the minerals in Katanga is needed, as well as additional efforts to achieve traceability of these minerals [20].

Indeed, several factors point to the occupational origin of the contaminants in the hair of the miners. The first is the chemical complexity of the minerals in Katanga, which has been amply demonstrated above. The complexity of minerals recovered in artisanal mining derives from the nature of the excavated deposits; these are typically composed of eluvium, which outcrops above the water table and undergoes several chemical reactions (e.g. oxidation) when exposed to other compounds [21]. Added to this is the excavation of other types of gangue, such as those in backfill and settling tanks; these include, for example, sulfides, sulfates, and chemicals contained in settling tanks [22]. In our case, even if the latter kind of excavation did not occur in Ruashi, the movement of miners to different sites, combined with the fact that hair has a long-term memory of old exposure, contributed to the complexity of the minerals and products to which the artisanal miners were exposed. Finally, the effects of natural contaminants present in any mining should not be excluded, which include aluminum, silica, arsenic, and their radioactive compounds and derivatives.

Ultimately, the explanation of the contaminants found in our samples of hair from artisanal miners should lie in the comparison with industrial miners who manipulate the same types of gangue. Indeed, differences between these two populations would emphasise the impact of treatment processes (e.g. crushing hammers, washing with water, and loading with shovels) and the lack of personal protective equipment.

\section{Digger contamination in comparison with non-diggers}

The analysis revealed a difference in contaminant concentrations among miners according to their respective workstations; for certain elements, the non-digger and digger levels were significantly different.

\begin{tabular}{|c|c|c|c|c|c|c|c|}
\hline \multirow{2}{*}{ Metals } & \multicolumn{3}{|c|}{ Non-diggers } & \multicolumn{3}{|l|}{ Diggers } & \multirow{2}{*}{$P$} \\
\hline & Median & $5^{\text {th }}$ percentile & $95^{\text {th }}$ percentile & Median & $5^{\text {th }}$ percentile & $95^{\text {th }}$ percentile & \\
\hline Aluminum & $3,396.620$ & 702.019 & $6,304.727$ & $3,158.928$ & 655.699 & $10,483.681$ & .792 \\
\hline Antimony & 0.599 & 0.196 & 1.587 & 0.505 & 0.166 & 1.316 & .055 \\
\hline Silver & 47.598 & 8.808 & 298.271 & 9.283 & 2.609 & 58.147 & .001 \\
\hline Barium & 25.960 & 12.662 & 58.601 & 28.404 & 15.064 & 103.191 & .254 \\
\hline Beryllium & 0.121 & 0.021 & 0.689 & 0.105 & 0.023 & 0.897 & .971 \\
\hline Cadmium & 3.964 & 1.665 & 7.340 & 0.970 & 0.143 & 3.521 & .001 \\
\hline Calcium & $2,892.162$ & 828.778 & $6,561.749$ & $3,196.970$ & $1,467.965$ & $10,809.026$ & .191 \\
\hline Cerium & 4.217 & 0.650 & 10.382 & 2.763 & 0.596 & 6.795 & .167 \\
\hline Chrome & 21.784 & 11.901 & 99.375 & 10.508 & 2.776 & 20.989 & .001 \\
\hline Cobalt & 264.512 & 125.313 & $7,705.622$ & 137.824 & 76.796 & 411.232 & .001 \\
\hline Copper & $2,100.926$ & 794.119 & $15,830.565$ & 819.337 & 396.640 & $1,984.743$ & .001 \\
\hline Tin & 2.693 & 1.487 & 5.304 & 1.493 & 0.226 & 2.588 & .001 \\
\hline Iron & $5,224.602$ & $2,748.125$ & $43,533.441$ & $6,069.128$ & $2,524.179$ & $87,676.446$ & .396 \\
\hline Magnesium & 641.780 & 334.691 & $1,445.879$ & 326.083 & 221.698 & 664.556 & .001 \\
\hline Manganese & 348.844 & 151.426 & $2,552.529$ & 376.043 & 161.327 & $5,641.597$ & .374 \\
\hline Mercury & 5.587 & 1.336 & 13.705 & 4.172 & 1.111 & 8.998 & .029 \\
\hline Molybdenum & 0.614 & 0.178 & 1.632 & 0.528 & 0.156 & 1.448 & .203 \\
\hline Nickel & 34.001 & 15.806 & 139.936 & 17.364 & 7.786 & 49.149 & .001 \\
\hline Lead & 70.737 & 10.518 & 295.102 & 61.369 & 14.654 & 225.137 & .320 \\
\hline Thallium & 0.049 & 0.028 & 0.098 & 0.108 & 0.045 & 0.316 & .001 \\
\hline Vanadium & 50.590 & 31.938 & 73.009 & 98.874 & 53.271 & $1,903.890$ & .001 \\
\hline Zinc & 409.339 & 289.213 & $1,469.386$ & 289.703 & 184.187 & 397.050 & .001 \\
\hline
\end{tabular}

Table 4: Metals traces values within artisanal miners according to workstations. 
We also noted that in this case, the use of dispersion measures gave different profiles of exposure for these two groups. This difference could be explained by the fact that non-diggers, who are in charge of different milling processes, come in more contact with the mineralised gangue than the diggers, and therefore are more exposed to the chemical components of the processed ore. Indeed, the processing techniques used by the non-diggers (e.g. washing with a sieve, crushing with a hammer, or the packaging of mineral concentrate) increase exposure to the chemical components of the ore, as opposed to the drilling of open-pits or opening of tunnels by the diggers [23]. This explanation is supported by the higher levels observed among diggers for elements which can be linked to excavation, such as thallium and vanadium.

In their study of small-scale mining in Tanzania, Bose-O'Reilly et al. [15] highlighted a difference in exposure between artisanal miners in charge of gold amalgamation and those involved in excavation. However, these results involved mercury exposure, an element that is added during the milling process but is not naturally found in the mineral gangue. In the case of artisanal mining in Katanga, mercury exposure is an issue for artisanal furnace workers; these workers rely on certain acids to obtain, by lixiviation, a liquid substance that can be captured to produce a concentrate called white amalgam. However, our sample population of artisanal miners did not include furnace workers. Nevertheless, Maponga and Ngorima have demonstrated the contribution of improved mining techniques to the reduction of environmental impacts of gold artisanal mining in Zimbabwe [24]. In our opinion, these successful attempts to improve operating procedures should be taken into consideration when revising artisanal miner protection and prevention standards, so that similar results may be made in the area of occupational health.

However, we did not observe any significant differences in the concentrations of metals between the miners either in terms of age, or in terms of seniority. This can be explained by the weak dispersion of our sample around the median. Indeed, differences reported in similar hair analysis involve groups of population relatively more various [25].

\section{Conclusions}

The above results attest to the reality and the large extent of exposure of artisanal miners in Katanga Province to chemical components in exploited mineralised gangue. This exposure showed to be greater for occupations related to the raw mineral processing phases as opposed to the extraction phase. Even though health problems associated with such exposure may not be currently observed, mainly due to the latency of the contamination, it is important to still develop strategies for prevention of toxicological hazards associated with artisanal mining. This should be done regardless of what measures are taken to reduce the environmental impacts of such exploitation.

Thus, it is necessary to not only improve our knowledge of the chemical composition of minerals in Katanga, but also to suggest technical processes and treatments that can reduce the hazards of direct contact (i.e., inhalation, ingestion, dermal contact, or radiation) with the contaminants involved in artisanal mining. Such suggestions should, for example, include a strategy that promotes the use of personal protective equipment (e.g. helmets, masks, and boots). Indeed, the contaminant concentrations that were found in this study result less from exogenous hair contamination than from endogenous contamination, since the samples were washed several times before being analysed. Therefore, the single use of certain kinds of protection, such as helmets, would only contribute a small amount to the prevention of exposure to metals during artisanal mining.
In addition, it will be important to start monitoring disease warning signs associated to chronic and professional exposure to the metals highlighted above. More generally, we call for measures to be taken for environment protection and prevention in order to fight against the impact artisanal mining has on the general population in the surrounding area.

\section{References}

1. Elenge $M M$ and De Brouwer C (2010). Revue de la littérature des pathologies liées aux risques toxicologiques dans l'exploitation minière artisanale au Katanga (R.D.C) J Int Santé Trav 1:28-39.

2. Mineralogy Database (Central Africa Royal Museum, Belgium)

3. Dewaele S, Muchez P, Vets J, Fernandez-Alonzo M, Tack L (2006) Multiphase origin of the $\mathrm{Cu}-\mathrm{Co}$ ore deposits in the western part of the Lufilian fold-and-thrust belt, Katanga (Democratic Republic of Congo). J Afr Earth Sci 46: 455-469.

4. Tshoza K (2007) Quid de la sécurité dans les exploitations minières artisanales cas de la carrière Pompage de la Rwashi. Rapports de la Table ronde sur l'impact de l'exploitation minière sur l'environnement du Katanga.

5. Hilson G (2009) Small-scale mining, poverty and economic development in sub-Saharan Africa: An overview. Res. Policy 34: 1-5.

6. Alsac N ( 2007) Analysis of heavy metals (As, Cd, Cr, Cu, Ni,Pb, $\mathrm{Zn}$ et Hg) in soils by ICP-MS. Ann. Toxicol. Anal 19: 37-41.

7. Society of Hair Testing (2005) Recommendations for hair testing in forensic cases. Ann Toxicol Anal 17: 217-219.

8. Chojnacka K, Gorecka H, Chojnacki A, Górecki H ( 2005) Inter-element interactions in human hair. Environ. Toxicol. Pharmacol 20: 368-374.

9. Elenge M M, Aubry J C, Jacob L, De Brouwer C (2011) Heavy metal in hair samples of 109 non-industrial (miners) population in Katanga. Santé 21: 41-46.

10. Agency for Toxic Substances and Disease Registry (ATSDR) (2009) Hair Analysis Panel Discussion: Factors influencing the interpretation of the analytical results.

11. Chojnacka K, Górecka H, and Górecki H (2010) Reference values for hair minerals of Polish students. Environ. Toxicol. Pharmacol 29: 314-319.

12. Chojnacka K, Górecka H, Górecki H (2006) The influence of living habits and family relationships on element concentration in human hair. Sci Total Environ 366: 612-620.

13. Kintz $\mathrm{P}(2007)$ Hair and diet assessment: Testing for trace elements by ICP MS. Ann. Toxicol. Anal $19: 65-69$

14. Bose-O'Reilly S. and Collaborators (2010) Health assessment of artisanal gold miners in Tanzania. Sci Total Environ 408: 796-805.

15. Bose-O'Reilly S and Collaborators (2010) Health assessment of artisanal gold miners in Indonesia. Sci Total Environ 408: 713-725.

16. Goullé J P, Mahieu L, Bonneau L, Laine G, Bouige $D$ and Lacroix C(2005) ICP-MS multi-elementary metal and metalloid validation in hair: reference values in 45 healthy volunteers. Ann. Toxicol. Anal 17: 97-102.

17. Banza CL, Nawrot TS, Haufroid V, Decrée S, De Putter T, et al. (2009) High human exposure to cobalt and other metals in Katanga, a mining area of the Democratic Republic of Congo. Environ Res109: 745-752.

18. Manda BK, Colinet G, André L, Manda AC, Marquet J -P et al. (2010) Evaluation de la contamination de la chaîne trophique par les éléments traces $(\mathrm{Cu}, \mathrm{Co}, \mathrm{Zn}$, $\mathrm{Pb}, \mathrm{Cd}, \mathrm{U}, \mathrm{V}$ et As) dans le bassin de la Lufira supérieure (Katanga/RD Congo) Tropicultura 28: 246-252.

19. Thys T, Decrée S, Burlet C, De Putter Th, Dupin L, et al. (2010) Characterisation of Heterogenite $(\mathrm{CoOOH})$ from oxidized copper-cobalt deposits in the Katang Copperbelt, D.R.Congo. Accessed on 29 January 2010.

20. Belgian Federal Ministry of Foreign Affairs, 2008. Task Force "MIRECA" Mineral Resources in Central Africa, Good Governance and Transparency in the mining sector - Traceability of ore and financial flows in the Copper (Cu) and Cobalt (Co) ore trade in the Democratic Republic of Congo (DRC) Accessed on 16 April 2008. 
Citation: Elenge MM, Aubry J, Jacob L, Brouwer CD (2011) Quantification of metal in the hair of copper miners in Katanga Province, Democratic Republic of Congo. J Environment Analytic Toxicol 1:114. doi:10.4172/2161-0525.1000114

21. Mees F, De Putter T, Decrée S, Dewaele S(2010) Petrographical features of malachite from Katanga as indicators of mineral formation processes preliminary results. In: Decrée S. and De Putter T. (eds) Le secteur minier de la République Démocratique du Congo à la croisée des chemins. Livre des résumés du Colloque, Tervuren, 73

22. Gorus J(2006) Artisanal mining in Katanga. Brussels Centre of African Studies Vrije Universiteit Brussel, Brussels.
23. Elenge $M M$ and De Brouwer C (2011) Identification of hazards in the workplaces of artisanal mining in Katanga. Int J Occup Med Environ. Health 24: 57-66.

24. Maponga $O$ and Ngorima C F (2003) Overcoming environmental problems in the gold panning sector through legislation and education: the Zimbabwean experience. J Clean Prod 11: 147-157.

25. Chojnacka K, G'orecka H, G'orecki H (2006) The effect of age, sex, smoking habit and hair color on the composition of hair. Environ Toxicol Pharmacol 22 $52-57$. 